\title{
Riskienhallinnalla toimivuutta perunamarkkinoille
}

\author{
Kati Jalonoja, Kyösti Pietola ${ }^{1)}$
}

${ }^{1)}$ MTT Taloustutkimus (MTTL),PL 3,00411 Helsinki, kati.jalonoja@mtt.fi, kyosti.pietola@mtt.fi

\section{Johdanto}

Ruokaperunamarkkinoille on tyypillistä se, että kysyntä on vakaata, mutta perunan hinta, ja etenkin sen tuottajahinta, vaihtelevat voimakkaasti tarjontatilanteen mukaan. Tämän vuoksi muutokset perunan kulutuksessa edellyttävät suhteellisen suuria hintamuutoksia. Perunan tarjonnan hetkellinenkin lisääntyminen tai väheneminen taas aiheuttaa suuria hintavaihteluita. Perunanviljelijän näkökulmasta tarjonnan lisääntymisestä tai vähenemisestä aiheutuva hintavaihtelu on ongelmallista, ja se korostaa onnistuneen markkinoinnin merkitystä maatilayrityksen taloudessa.

Tässä tutkimuksessa estimoidaan ruokaperunamarkkinoita kuvaava ekonometrinen malli. Mallin perusteella arvioidaan markkinoiden tunnuspiirteitä ja riskienhallinnan merkitystä perunantuottajan näkökulmasta. Tutkimuksen aineistona käytettiin ruokaperunan tuottajahintoja, joita on tilastoitu vuodesta 1990. Tilastoaineiston on kerännyt Elintarviketieto Oy (2001) ja se sisältää 1. luokan ruokaperunan myyntimäärillä painotetut rahdittomat viljelijähinnat kahden viikon välein raportoituna. Tilastoaineisto kattaa vuodet 1990-2001. Tutkimuksessa käytettiin irtoperunan hintaa, jonka osuus vähittäiskaupan myynnistä on noin puolet myydystä perunamäärästä.

Ruokaperunantuottaja on kiinnostunut ennustamaan sekä perunasadon odotettua tuottoa että tuoton varianssia varastointikauden sisällä. Koska ruokaperunan hinnan varianssin odotettu kasvaminen varastointikauden edetessä mallitettiin yhdessä hintasarjan kanssa, estimoitiin tutkimusmenetelmänä käytetyn $\mathrm{ARCH}-m a l l i n$ parametrit suurimman uskottavuuden menetelmällä.

\section{Ekonometrinen malli}

Perunan hinnan logaritmimuunnosta ( $\left.\ln p_{t+1}\right)$ selitettiin autoregressiomallilla, $\operatorname{AR}(k)$, jossa viipeiden lukumäärä on $k$. Yhtälöön lisättiin satovuoden $(\tau)$ kokonaissato $\left(A_{\tau}\right)$, kausivaihtelua mittaava polynomifunktio $S(t)$, varastoitu ruokaperunamäärä $\left(I_{t}\right)$ ja joukko apumuuttujia $(D)$. Näin päädyttiin malliin:

$$
\ln p_{t+1}=\phi_{0}+\sum_{i=0}^{k} \phi_{1+i} \ln p_{t-i}+\sum_{j=1}^{J} \alpha_{j} D_{j} \ln A_{\tau}+S(t)+\theta_{1} D_{I} I_{t}+\theta_{2} D_{E U}+\varepsilon_{t+1}
$$

missä $\phi, \alpha$, ja $\theta$ ovat parametreja ja $\varepsilon_{t+1}$ on virhetermi.

Kokonaissadon $\left(A_{\tau}\right)$ odotetaan vaikuttavan vain markkinointikauden ensimmäisiin hintanoteerauksiin ja kauden edetessä hinnat sisältävät myös satoinformaation. Tämän vuoksi kokonaissato kerrottiin apumuuttujalla $D_{j}$, joka saa arvon yksi hintanoteerauksella numero $j=1, \ldots J$. Muulloin $D_{j}=0$. Käytetyn notaation mukaan hintanoteerauksesta numero $J$ lähtien hinnat sisältävät kaiken satoinformaation eikä satomuuttujaa enää tarvita mallissa.

Vuosittain toistuvat hintojen kausivaihtelut otettiin huomioon polynomilla $S(t)=\xi_{1} t_{s}+\xi_{2} t_{s}^{2}$. Aikaindeksi $t_{s}=1, \ldots, T$ mittaa aikaa vain markkinointikausien sisällä niin, että se saa arvon yksi syksyn ensimmäisen hintanoteerauksen kohdalla ja arvon $\mathrm{T}$ kevään viimeisen hintanoteerauksen kohdalla. Kirjaimet $\xi$ ovat parametrejä.

Apumuuttuja $D_{I}$ saa arvon yksi hetkellä, jolloin viljelijäkyselyyn perustuvat perunan varastomääräennusteet $I_{t}$ tulevat markkinoille. Muulloin se saa arvon nolla. Suomen EU jäsenyyden mahdollisesti aiheuttama hintaprosessin muutos mitataan apumuuttujalla $D_{E U}$, joka saa arvon nolla ennen vuotta 1995 ja vuodesta 1995 lähtien arvon yksi.

Hintasarjaa kuvaavan mallin tilastolliset ominaisuudet riippuvat ratkaisevasti siitä, onko sarja stationaarinen vai ei. Lisäksi stationaarisuustestien voima on heikko etenkin, jos sarjassa epäillään olevan rakenteellinen muutos (Leybourne and Newbold 2000). Tämän vuoksi stationaarisuustesteissä 
käytettiin nollahypoteesina sekä epästationaarista yksikköjuuriprosessia että stationaarista prosessia (Dickey ja Fuller 1979, Kwiatkowski ym. 1992). Koska hintasarja osoittautui epästationaariseksi yksikköjuuriprosessiksi, sen testaamista jatkettiin estimoimalla malli differenssimuodossa:

$$
\Delta \ln p_{t+1}=\phi_{0}+\sum_{i=0}^{k} \mu_{1+i} \Delta \ln p_{t-i}+\sum_{j=1}^{s} \alpha_{j} D_{j} \ln A_{\tau}+S(t)+\theta_{1} D_{I} I_{t}+\theta_{2} D_{E U}+\varepsilon_{t+1}
$$

missä $\Delta \ln p_{t+1}=\ln \left(p_{t} / p_{t-1}\right)$.

Jotta voimme testata hintasarjan symmetrisyyttä suhteessa eksogeenisiin hintashokkeihin, hintasarjan (2) virhetermi pilkottiin seuraavasti

$$
\varepsilon_{t+1}=\eta_{0}+\eta_{1}\left(D_{+}\right) \varepsilon_{t}+\eta_{2} \varepsilon_{t}+v_{t+1}
$$

missä $D_{+}$on apumuuttuja ja se saa arvon yksi jos $\varepsilon_{t}>0$ ja muulloin arvon nolla. $\eta$ kirjaimet ovat parametreja ja $v$ on riippumaton ja identtisesti jakautunut virhetermi. Nollahypoteesina on symmetrinen hintasarja, jolloin $\eta_{l}=0$. Epäsymmetrinen hintaprosessi puolestaan antaisi viitteitä siitä, että perunakaupan osapuolten markkinavoima on epätasapainossa.

Hintasarjan varianssin ominaisuudet testattiin yhtälössä:

$$
\sigma_{t+1}^{2}=\psi_{0}+\sum_{j=0}^{l} \psi_{j+1} \varepsilon_{t-j}^{2}+\varphi D_{E U}+\beta_{3} t_{s}+\beta_{4} t_{s}^{2}+u_{t+1}
$$

missä ${\sigma_{t+1}}^{2}$ on perunan hinnan ehdollinen varianssi (volatiliteetti) hetkellä $t+1 \cdot \mathcal{E}_{t-j}^{2}$ on virhetermi korotettuna toiseen potenssin ja viivästettynä $j$ periodilla. Myös tässä yhtälössä testataan apumuuttujan $D_{E U}$ avulla Suomen EU-jäsenyyden aiheuttama murros. Kreikkalaiset kirjaimet $\psi, \varphi$ ja $\beta$ ovat parametrejä ja $u_{t+1}$ on virhetermi. Hintojen volatiliteetin odotetaan kasvavan kauden edetessä, koska kysyntä muuttuu varastointikauden lähestyessä loppuaan yhä joustamattomammaksi. Nollahypoteesin alla volatiliteetti on kuitenkin vakio.

\section{Aineisto}

Perunan hinnat ovat pakkaamattoman perunan tuottajahintoja. Hinnat havaitaan kahden viikon välein. Markkinointivuosi alkaa syksyllä lokakuussa viikolla numero 43 ja päättyy seuraavana keväänä toukokuussa viikolla numero 22. Yhden markkinointivuoden pituus on tutkimusaineistossa näin ollen kahdeksan kuukautta ja siinä on 16 hintahavaintoa. Aineisto kattaa jakson tammikuusta 1990 joulukuuhun 2000 ja siinä on kaikkiaan 176 havaintoa (kuva 1). 


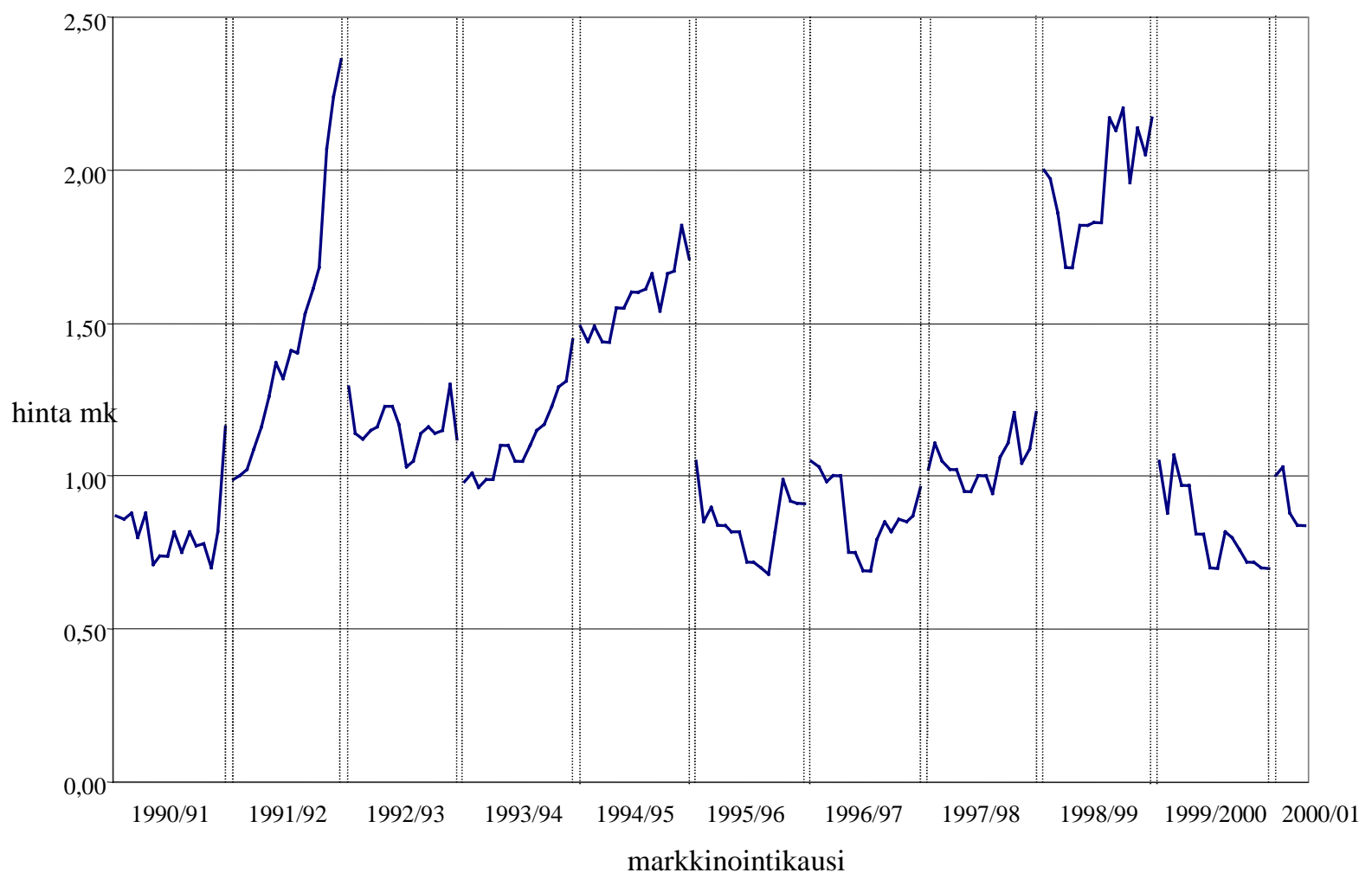

Kuva 1. Ruokaperunan hintasarja markkinointikausilla 1990-2000.

\section{Tulokset ja johtopäätökset}

Tutkimustulosten mukaan perunan tuottajahinnat ovat erittäin joustavia perunan kokonaissatomäärän suhteen. Kokonaissatomäärän kasvu kymmenellä prosentilla laskee ruokaperunan hintaa kaksikymmentä prosenttia ja tuottajan tuloja kahdeksantoista prosenttia. Tulos puoltaa näkemystä, että ruokaperunan tuottajan hyvä tulos tehdään hyvällä hinnalla -ei hyvällä sadolla.

Ruokaperunan hinnalle on myös ominaista se, että hintashokit ovat pysyviä markkinointikauden loppuun asti. Tämä hintashokkien pysyvyys lisää perunavarastojen pitämiseen liittyviä hintariskejä. Hintojen yllättäen laskiessa tai noustessa, ne eivät todennäköisesti enää palaa ennalleen saman varastointikauden aikana. Suomen markkinoilla perunan varastointi ilman sopimuksia eli ns. avointen käteismarkkinoiden varassa näyttäisi tulosten mukaan olevan kannattavaa vain silloin, kun kotimaista perunaa on vähän markkinoilla.

Hintashokkien pysyvyydellä on tärkeitä seurauksia optimaalisiin perunan markkinointipäätöksiin. Hintojen yllättäen laskiessa eli negatiivisen hintashokin jälkeen ei perunoiden myyntiä kannata siirtää eteenpäin, sillä hinnat eivät todennäköisesti palaa niiden pitkän aikavälin keskimääräiselle tasolle. Poikkeuksellisen suuri perunasato taas on perunantuottajalle riski, koska perunan kysyntä ei lisäänny, vaikka sen hinta laskee. Siksi perunantuottajien tulisi suojautua hintariskeiltä jo keväällä ennen perunan istutusta eli ennen kuin markkinoilla on tietoa perunasadosta. Sadonkorjuun jälkeisillä toimenpiteillä ei hintariskeihin voida enää vaikuttaa, sillä hintariskit ovat silloin jo toteutuneet. Nykyisessä markkinatilanteessa tulisi tutkia mahdollisuutta alentaa perunan hinnan vaihtelua ja vakauttaa perunamarkkinoita johdannaismarkkinoiden avulla.

Tulokset eivät anna viitteitä perunan hintavolatiliteetin kasvamisesta merkitsevästi varastointikauden edetessä. Tulos selittynee sillä, että kylläisinä markkinointivuosina hinnat ovat koko vuoden alhaalla. Tulokset eivät myöskään antaneet näyttöjä, että jommallakummalla kaupan osapuolella olisi merkitsevää markkinavoimaa joka näkyisi epäsymmetrisenä hintaprosessina. 
Taulukko 1. Parametriestimaatit yhtälössä (2). Parametrien keskivirheet ovat suluissa.

\begin{tabular}{|c|c|c|c|c|}
\hline & \multicolumn{2}{|c|}{ Koko aineisto $^{\text {a) }}$} & \multicolumn{2}{|c|}{ EU vuodet $(1995-)^{b)}$} \\
\hline & 1 viive $(i=0)$ & 2 viivettä $(i=1)$ & 1 viive $(i=0)$ & 2 viivettä $(i=1)$ \\
\hline \multirow{2}{*}{ Vakio $\left(\phi_{0}\right)$} & -0.0438 & -0.0431 & $-0.0713 * *$ & $-0.0715 * *$ \\
\hline & $(0.025)$ & $(0.025)$ & $(0.0000)$ & $(0.000)$ \\
\hline \multirow[t]{2}{*}{ Viivästetty hinta $(\rho)$} & $0.999 * *$ & $1.00 * *$ & $0.999 * *$ & $1.00 * *$ \\
\hline & $(0.023)$ & $(0.024)$ & $(0.025)$ & $(0.025)$ \\
\hline \multirow[t]{2}{*}{ Viivästetty hintadifferenssi $\left(\mu_{l}\right)$} & $-0.184 *$ & $-0.198 *$ & -0.197 & -0.204 \\
\hline & $(0.087)$ & $(0.090)$ & $(0.11)$ & $(0.11)$ \\
\hline \multirow[t]{2}{*}{ Kahdesti viivästetty hintadifferenssi $\left(\mu_{2}\right)$} & - & -0.0598 & - & -0.0316 \\
\hline & & $(0.092)$ & & $(0.10)$ \\
\hline \multirow[t]{2}{*}{ Satovaikutus syksyn 1 . hintaan $\left(\alpha_{l}\right)$} & $-1.89 * *$ & $-1.89 * *$ & $-2.33 * *$ & $-2.33 * *$ \\
\hline & $(0.26)$ & $(0.26)$ & $(0.32)$ & $(0.32)$ \\
\hline \multirow[t]{2}{*}{ Satovaikutus syksyn 2 . hintaan $\left(\alpha_{2}\right)$} & -0.127 & -0.121 & -0.298 & -0.296 \\
\hline & $(0.26)$ & $(0.26)$ & $(0.32)$ & $(0.32)$ \\
\hline \multirow[t]{2}{*}{ Trendi satokauden sisällä $\left(\xi_{l}\right)$} & 0.0074 & 0.0071 & 0.0100 & 0.0098 \\
\hline & $(0.0063)$ & $(0.0063)$ & $(0.0079)$ & $(0.0079)$ \\
\hline \multirow{2}{*}{ Toisen asteen termi satokauden sisällä $\left(\xi_{2}\right)$} & -0.0001 & -0.0000 & -0.0002 & -0.0002 \\
\hline & $(0.0004)$ & $(0.0004)$ & $(0.0004)$ & $(0.0004)$ \\
\hline \multirow{2}{*}{ Perunavarastojen määrä $\left(\theta_{l}\right)^{\mathrm{c})}$} & 0.0023 & $0.0009 * *$ & -0.0019 & -0.0033 \\
\hline & $(0.017)$ & $(0.0000)$ & $(0.023)$ & $(0.022)$ \\
\hline \multirow[t]{2}{*}{ EU -apumuuttuja $\left(\theta_{2}\right)$} & -0.0209 & -0.0221 & - & - \\
\hline & $(0.014)$ & $(0.014)$ & & \\
\hline
\end{tabular}

a) Havaintojen lukumäärä on 176 .

b) Havaintojen lukumäärä on 96 .

c) Varastoinventaarioiden estimaatit rajoitettu yhtä suuriksi. Ne eivät poikenneet merkitsevästi toisistaan.

Yksi tähti (*): merkitsevä alle 5 prosentin riskillä. Kaksi tähteä $(* *)$ : merkitsevä alle prosentin riskillä.

\section{Kirjallisuus}

Leyborne, S.J. \& Newbold, P. 2000. Behavior of Dickey-Fuller t-tests when there is a break under the alternative hypothesis. Econometric theory 16: 779-789.

Dickey, D.A. \& Fuller, W.A. 1979. Distribution of estimates for autoregressive time series with unit root. Journal of American Statistical Association 74: 427-431.

Elintarviketieto Oy. 2001. Tilastot 1. luokan ruokaperunan myyntimäärillä painotetuista rahdittomista viljelijähinnoista 1990-2000. Maa- ja metsätalousministeriön tietopalvelukeskus.

Kwiatkowski, D., Phillips, P., Schmidt, P. \& Shin, Y. 1992. Testing the null hypothesis of stationarity against the alternative of a unit root. Journal of Econometrics 54: 154-178. 